\title{
GRAMÁTICA E ENSINO: UMA PERSPECTIVA DE INTERAÇÃO
}

\section{Grammar and teaching: perspective of interaction}

Natália Penitente Andrade, UNEB ${ }^{1}$

RESUMO: A pesquisa tem como objetivo geral analisar se a gramática normativa é desenvolvida no livro didático do $9^{\circ}$ ano da Coleção Teláris, em uso no município de Teixeira de Freitas-BA, de forma integrada com a leitura, interpretação, produção textual e análise linguística, a partir dos gêneros textuais. Como objetivos específicos, busca verificar se há uma diversidade de gêneros textuais orais e escritos no livro didático bem como se as atividades contemplam situações formais e informais de uso. Além disso, tem como proposta propiciar discussões e reflexões sobre a importância da escolha do manual didático. Para tanto, utilizase como referencial teórico Marcuschi e Cavalcante (2005), Marcuschi (2010), os PCNs (1998), Antunes (2003), Possenti (1998), Lopes-Rossi (2002), Bezerra (2005), dentre outros. A partir de uma pesquisa qualitativa, constata-se que os aspectos gramaticais são contextualizados, colaborando com a reflexão crítica do aluno, bem como partem de um gênero textual para as definições. Dessa forma, conclui-se que as atividades envolvendo a gramática, frequentemente, perpassam a leitura, a interpretação, a produção textual e a análise linguística, propiciando uma aprendizagem significativa para o aluno. Também é possível afirma que o livro didático contempla uma diversidade de gêneros textuais e orais e apresenta a distinção das situações formais e informais da língua.

PALAVRAS-CHAVE: Gramática; Ensino; Livro didático; Gêneros Textuais e Orais; Competência discursiva.

\begin{abstract}
The main objective of this research is to analyse if the development of normative grammar is carried out in an integrated approach of reading, interpretation, textual production and linguistic analysis in the $9^{\text {th }}$ Grade Textbook (Teláris Collection), which is currently being used in the city of Teixeira de Freitas, in the state of Bahia. The research specific objectives aim to verify if there is a variety of oral and textual genres in the textbook, also if the activities include informal and formal situations of language use. Furthermore, it is intended at providing discussions and reflections about the importance of choosing the textbook. In order to achieve our objectives, we used the following authors as theoretical reference: Marcuschi e Cavalcante (2005), Marcuschi (2008), os PCNs (1998), Antunes (2003), Possenti (2001), Lopes-Rossi (2006), Bezerra (2005) and others. Based on a qualitative methodology, it was possible to observe that the grammatical aspects are contextualized in a textual genre, thus helping the student critical thinking. Thereby, it is concluded that the grammar activities usually are based on reading, interpretation, writing and linguistic analysis which provide the student with a significant learning process. The textbook also offers a variety of oral and textual genres and introduces the distinction of informal and formal situations of language use.
\end{abstract}

Keywords: Grammar; Education; Textbook; Oral and Textual Genres; Discursive Competence.

\footnotetext{
${ }^{1}$ Bolsista de Iniciação Científica pela Fundação de Amparo à Pesquisa do Estado da Bahia - FAPESB. Email: nataliapeniitente@ hotmail.com.

Trabalho orientado por Aline Maria dos Santos Pereira (UNEB). Email: allinemaria@ hotmail.com.
} 


\section{INTRODUÇÃO}

Desde o início dos anos noventa houve um número significativo de estudos sobre o livro didático de Língua Portuguesa. O mesmo permanece como um dos materiais básicos na organização pedagógica e por isso é fundamental que continue a ser descrito, debatido, avaliado no esforço coletivo de ampliar sua qualidade (MARCUSCHI,2005).

Dentro da perspectiva do trabalho com gêneros orais e com a gramática normativa devese estabelecer uma prática constante de escuta de textos orais, leitura de textos escritos, de produção de textos orais e escritos. Pois, permitirá, por meio de análises e reflexões sobre os múltiplos aspectos envolvidos, a expansão e a construção de instrumentos que progressivamente ampliam a competência discursiva do aluno; bem como abordar os conceitos gramática e contextualizá-la, partindo do gênero textual para a definição, porque viabiliza a uma compreensão acerca dos aspectos da língua.

A partir dessas afirmações é notória a importância de conter tais recursos nos manuais didáticos, pois possibilitará o desenvolvimento da competência discursiva dos alunos.

Diante o exposto, o objetivo geral desse trabalho é analisar se a gramática normativa é desenvolvida no livro didático do $9^{\circ}$ ano, Coleção Teláris, de forma integrada com a leitura, interpretação, produção textual e análise linguística, a partir dos gêneros textuais, visando à competência discursiva do aluno. Como objetivos específicos, o trabalho tem a intenção de: a) verificar se há uma diversidade de gêneros textuais escritos e orais no livro didático e se as atividades contemplam situações formais e informais de uso; b) ressaltar a relevância do trabalho com a diversidade de gêneros textuais no ensino de Língua Portuguesa; e, por fim, c) propiciar discussões e reflexões sobre a importância do manual didático.

A presente pesquisa faz parte de um subprojeto de Iniciação Científica financiada pela Fundação de Amparo à pesquisa do Estado da Bahia (FAPESB). O livro analisado foi o do $9^{\circ}$ ano, da coleção Teláris, elaborado pelas autoras Ana Trinconi Borgatto, Terezinha Bertin e Vera Marchezi, e utilizado pelas escolas públicas municipais de Teixeira de Freitas. Para tanto, utilizamos como referencial teórico: Parâmetros Curriculares Nacionais (1998), Beth Marcuschi (2005), Marcuschi (2010), Geraldi (1999), Lopes-Rossi (2002), Bazerman (2005), Possenti (1998), dentre outros.

A metodologia utilizada foi de caráter qualitativo-quantitativo. Realizou-se a contagem da presença dos gêneros textuais para observar a diversidade no livro didático; e na sequência, 
realizamos a análise qualitativa, na qual descrevemos as atividades analisando se as mesmas contemplam a leitura, interpretação, produção de tex to e análise linguística de forma articulada.

Esperamos que a pesquisa auxilie na reflexão acerca dos livros didáticos para o desempenho linguístico dos alunos nas escolas e contribua para a formação dos discentes de Letras e futuros leitores dessa pesquisa.

\section{IMPORTÂNCIA DO LIVRO DIDÁTICO: TRAJETÓRIA E PERSPECTIVA DE ENSINO}

O Fundo Nacional de Educação (FNDE), (1968) descreve a trajetória do Programa nacional do livro didático (PNLD), e destaca a existência de 80 anos. Desde 1929, no decorrer teve diferentes nomes e formas, mas é voltado para educação básica com exceção da educação infantil; é o mais antigo programa de livro didático. O Fundo Nacional de Desenvolvimento da Educação (FNDE) é o mais antigo dos programas voltados à distribuição de obras didáticas aos estudantes da rede pública e compra e distribui livros didáticos para o ensino Fundamental, Médio e Educação de Jovens e Adultos. Para tanto, ocorre um processo, sendo: adesão, editais, inscrições dos editais, avaliação, guia do livro, escolha, pedido, aquisição, produção, análise de qualidade física, distribuição e recebimento. Além disso, os livros são feitos para serem utilizados por três anos e beneficiar mais de um aluno. $\mathrm{O}$ aluno tem direito a cada um exemplar das disciplinas, sendo tanto para o ensino fundamental e médio. Fora criado o Sistema de Controle de Remanejamento e Reserva Técnica (SISCORT) com objetivo de registrar e controlar o remanejamento de livros e a distribuição da Reserva Técnica, no âmbito do PNLD.

Diante das políticas envolvidas no desenvolvimento e aquisição, deve-se mencionar e ressaltar a importância do livro didático enquanto suporte metodológico para os professores. Assim, o livro didático, de acordo com Marcuschi (2005, p. 238), “ocupa um lugar significativo, pois, faz-se necessário que continue a ser descrito, debatido, avaliado no esforço coletivo para ampliar sua qualidade”. A qualidade do livro didático está relacionada às necessidades do professor e de seus alunos, oferecendo subsídios e alternativas produtivas ao trabalho escolar.

O livro didático é um material instrumentalizado com a finalidade de auxiliar, guiar e facilitar a prática; em sala de aula é condutor de ideologia nacional e sua função é de conter textos literários, diversidade de gêneros textuais, trajetória da literatura e pensamentos humanos, também informar sobre um equívoco provocado pela sociedade, que é o preconceito linguístico. Deve-se ensinar a língua portuguesa e suas variações, reflexões sobre o que é 
língua e o que é gramática. Dessa forma, quando o aluno conhece questões linguísticas e discursivas amplia sua competência discursiva e criam-se contextos efetivos de uso da linguagem (Marcuschi, 2005).

Marcuschi (2005) reitera, dentro da mesma perspectiva dos Parâmetros Curriculares Nacionais (PCNs), que quando a escola ensina o aluno a aprender a falar e pensar sobre a própria linguagem; bem como, realiza uma atividade de natureza reflexiva, contribuirá progressivamente para a ampliação da competência discursiva. Destaca uma afirmação pertinente, sendo que, ao admitirmos que a educação é um direito fundamental e que a escola desempenha um papel essencial na formação para a cidadania, será inevitável concluir que o acesso às práticas de letramento, deve estar no foco do trabalho em sala de aula.

O livro didático de Língua Portuguesa (LDLP) deve estar em sintonia com as aspirações da sociedade, em termos da formação básica com qualidade social para as crianças e os jovens brasileiros, em uma perspectiva sociointeracionista, na qual o conhecimento é compreendido e apreendido como construção histórico-social.

Nessa perspectiva, o mesmo autor destaca aspectos positivos e negativos dos livros didáticos são eles: 1 . O crescente estudo nos anos noventa tratou de questões relativas ao livro didático, de forma ampla e no livro de língua portuguesa; 2. A importância dos estudos no livro didático de língua portuguesa, pois é uma ferramenta do professor em sala de aula. Em contrapartida, a autora destaca um aspecto negativo diante de suas avaliações e análises, que é: 1. Os temas repetitivos de produção de escrita, levando o aluno a elaborar redações que se configuram como mero exercício de escrita, bem como características endógenas.

\section{GÊNEROS TEXTUAIS NO ENSINO: IMPORTÂNCIA E APLICABILIDADE}

Marcuschi (2010, p.19) aponta os gêneros textuais como "entidades sóciodiscursivas e formas de ação social incontornáveis de qualquer situação comunicativa". Dessa forma, os gêneros surgem como formas da comunicação, atendendo a necessidades de expressão do ser humano, moldados sob influência do contexto histórico e social das diversas esferas da comunicação humana. Tendo isso em vista, nota-se que os gêneros são dinâmicos e podem se modificar com o passar do tempo, também podem surgir e desaparecer e se diferenciar de uma região, ou cultura, para outra.

O PCNs (1998) abordam a necessidade de contemplar na escola e nos livros didáticos uma diversidade de gêneros para que o sujeito desenvolva habilidades de oralidade, leitura e escrita, destaca-se que "cabe a escola organizar as atividades curriculares relativas ao ensino- 
Lopes-Rossi (2002) afirma que ensinar os gêneros textuais proporciona autonomia e domínio no funcionamento da língua em situações de comunicação dos alunos. Ainda destaca que cabe ao professor criar condições para que os alunos possam apropriar-se das características discursivas e linguísticas de gêneros diversos e de situações de comunicação real; e isso pode ser feito com projetos pedagógicos.

Ao estabelecer um paralelo com a autora supracitada, na perspectiva de projetos pedagógicos, Bezerra (2005) aborda alguns gêneros como exemplos para um projeto pedagógico, podendo ser: rótulos de produto, bulas de remédio, propagandas de produtos, propagandas políticas, etiquetas de roupas, manuais de instrução de equipamentos, contratos, nota fiscal. E para a leitura de entretenimento: poesia, romance, verbete de dicionário, lenda, fábula, cordel, adivinha, piada, mapa, letra de música. Nota-se uma possível alternativa de trabalho com os gêneros na sala de aula.

Marcuschi (2010, p.1), dentro da perspectiva de definições do gênero textual, aborda que os gêneros textuais são historicamente vinculados à vida cultural e social, advindos de um trabalho coletivo, "os gêneros contribuem para ordenar e estabilizar as atividades comunicativas do dia-a-dia." Afirma também que os gêneros textuais caracterizam-se por ser altamente maleáveis e dinâmicos; e que com as inovações tecnológicas houve um aumento quantitativo dos gêneros textuais existentes em relação às sociedades anteriores.

\section{REFLEXÕES GRAMATICAIS: UMA PERSPECTIVA DE ENSINO}

Sob o viés da reflexão gramatical, os PCNs (1998) definem que não se justifica tratar o ensino gramatical desarticulado das práticas de linguagem, destacando que não se deve trabalhar a gramática de forma descontextualizada, bem como uma prática pedagógica vai da metalinguagem para a língua por meio de exemplificação. Torna-se necessário fazer análises de como ensinar e deve-se priorizar a função das necessidades apresentadas pelos alunos nas atividades de produção, leitura e escuta de textos.

Possenti (1998), nessa mesma direção sob aspectos gramaticais, explana que, para se trabalhar gramática deve-se entender o conceito. Entende-se primeiramente que gramatica é um "conjunto de regras", abordando três perspectivas: conjunto de regras que devem ser seguidas, caracterizando por gramática normativa; conjunto de regras que são seguidas, gramáticas descritivas; conjunto de regras que o falante da língua domina, gramáticas internalizadas. As duas primeiras maneiras dizem respeito ao comportamento oral ou escrito dos membros de uma comunidade. A terceira maneira de definir a expressão refere-se a 
hipóteses sobre aspectos da realidade mental dos mesmos falantes. Diante disso, detalha três noções, caracterizando três tipos de gramáticas.

Ao compreendermos os conceitos de gramáticas a partir de Possenti (1998), partiremos para a reflexão gramatical na prática que os PCNs (1998) abordam, que não se justifica tratar o ensino gramatical desarticulado das práticas de linguagem; a gramática não deve ser ensinada de forma descontextualizada. Deve-se a utilização de uma prática pedagógica que parte do texto, por meio de exemplificação, para os conceitos, tendo-se em mente a questão de para que ensinar e como ensiná-la.

Nessa linha de pensamento, acerca da gramática normativa, Soares (2003) aborda pontos fundamentais na questão no ensino de gramática. Para o autor os manuais de gramática normativa contêm normas de bom uso da língua para falar e escrever bem, porém criam-se preconceitos de toda a espécie por basear-se em parâmetros muitas vezes equivocados, como: purismo, classe social de privilégio (econômico, cultural, político) e autoridade (gramática, bons escritores), lógica e história (tradição) (Soares,2003).

Ainda afirma que é necessário ensinar a gramática normativa, pois desenvolve a competência comunicativa do aluno de forma que ele seja capaz de utilizar adequadamente em determinados contextos a língua, bem como a variedade padrão. Saber a língua em sua variedade é muito importante para o indivíduo.

Portando, faz-se necessário que o professor de Língua Portuguesa passe a ver o ensino de gramática como algo muito mais amplo que aquilo que tradicionalmente se tem como gramática normativa em nossas aulas de língua materna de Língua Portuguesa.

\section{ORALIDADE E ENSINO DE LÍNGUA: UMA QUESTÃO POUCO FALADA}

Marcuschi (2010) aborda que a fala é uma atividade central bem mais que a escrita no dia-a-dia. Porém as instituições escolares valorizam e a centralidade na escrita. $\mathrm{O}$ autor destaca que não deve-se tratar essa postura na sala de aula bem como não utilizar o argumento de que já que utilizamos tanto a fala no dia-a-dia e não deve ser objetivo de estudo em sala de aula. Atualmente é recorrente discursões acerca de preocupações com o trabalho com a oralidade pelos responsáveis pelo ensino de língua.

O autor também delimita um tema específico para ser analisado no capítulo: Como se apresenta hoje a concepção e análise da língua falada nos LDP e quais as alternativas para a superação do problema? Para a abordagem nos manuais didáticos trata-se de observar como é posto a noção de língua. Uma breve análise constata-se: trabalho com regras (no estudo 
gramatical); informações textuais (no exercício de compreensão) textos escritos (na atividade de redação).

Conforme Marcuschi (2010), convém esclarecer as noções de língua. Embora, aparentemente pareça sinônimos língua e linguagem tem carga teórica diversa. Nos livros didáticos, a língua é clara, uniforme, desvinculada dos usuários, descolada da realidade, semanticamente autônoma e a-histórica.

A escola tem o papel central de: ensinar a escrita, a inserção de reflexões e dados sobre a língua falada é pouco falada nos manuais didáticos. Os autores dos manuais ainda não sabem como situar o estudo da fala. O mesmo autor salienta uma possível maneira que não se trata de ensinar a falar, mas de determinar o lugar do estudo da fala em sala de aula, seja especificando os aspectos nos quais o estudo tem a contribuir. Também não se trata de transformar a fala em um tipo de conteúdo autônomo no ensino de língua: ela deve ser vista integralmente e na relação com a escrita.

Desse modo, um dos estudos centrais sobre a fala é a variação. Marcuschi (2010) evidencia um exemplo pertinente do trabalho com a oralidade, que contribui com a formação cultural e na preservação de tradições não escritas, um exemplo é os contos populares ainda tão vivo em nossos povos, não só no interior, mas também em áreas urbanas. Também, dedicarse o estudo da fala é também uma oportunidade de esclarecer aspectos relativos ao preconceito e à discriminação.

Uma visão dos manuais didáticos é aquela que não considera a fala como um lugar de erro, assim, nota-se um descaso em relação à oralidade, porém registra-se que nos últimos anos há um progressivo aumento de sugestões de estudos sobre a fala e os PCNs (1998) têm uma concepção de oralidade mais nítida.

Marcuschi (2010) descreve uma análise de como a língua oral nos livros didáticos é posta: em muitos casos, confundem-se gírias com dialetos e regionalismo; a língua falada parece ser tratada como uma questão lexical; os exercícios com a linguagem dita coloquial na sua relação com a linguagem culta; a língua falada não são sistemáticas mas pontualizadas e a propósito de elementos não centrais; privilegiam as atividades de oralização, dentre outros.

Constata-se que é fundamental que os professores tenham a noção de língua para sustentar uma visão de língua falada de maneira coerente e produtiva; bem como um concepção de língua falada e língua escrita, sem privilegiar uma ou outra e evitando dicotomias.

Para tanto, nota-se que faz necessário compreender que o ensino da língua na escola não visa formar linguistas mas apenas ensinar aos alunos a perceberem a riqueza que envolve 
o uso efetivo da língua como um patrimônio maior, e que a língua será a grande ferramenta diária da qual ninguém poderá abdicar durante toda sua vida.

Por fim, Marcuschi (2010) ressalta sugestões de atividade para análise da língua falada: Audição de fitas om fala das mais diversas regiões; debate a respeito da formação e preconceitos; análise da polidez e sua organização na fala; identificações dos papéis dos interlocutores e dos diversos gêneros produzidos; discursões de como desenvolver os temas; identificação de alguns aspectos típicos de produção oral; análise de reescritura de um diálogo dos que aparecem nos livros em língua escrita padrão.

\section{ANÁLISE DO LIVRO DIDÁTICO DO 9 ANO - I UNIDADE - CAPÍTULO I POEMAS E FORMAS DE LINGUAGEM.}

O quadro abaixo apresenta os gêneros textuais orais e escritos presentes no livro didático do $9^{\circ}$ ano. Considera-se importante a presença dos mesmos, pois pode desenvolver no aluno a percepção da riqueza que envolve o uso efetivo da língua, bem como amplia a competência discursiva para os usos dos diferentes gêneros orais. Observe o quadro abaixo. Gêneros orais presentes no capítulo I e V do livro didático do $9^{\circ}$ são:

\begin{tabular}{|c|c|}
\hline Gêneros Orais & Gêneros textuais \\
\hline $\begin{array}{c}\text { diálogo; letra de música; filme; } \\
\text { notícia; propaganda; debate Relato de } \\
\text { experiência de vida, discussão, Peça } \\
\text { teatral; dramatização; seminário, } \\
\text { piada, anedota, causo. }\end{array}$ & $\begin{array}{c}\text { música, quadro, fotografia, poema, mapa, tabela, } \\
\text { glossário, romance, pintura, tira, esquema, conto, } \\
\text { crônica, resumo, noticia, debate, capa de livro, } \\
\text { quadrinho, revista, gráfico, roteiro, charge, reportagem, } \\
\text { artigo de opinião, logotipo, anuncio, haicai, texto } \\
\text { científico, biografia. }\end{array}$ \\
\hline
\end{tabular}

A partir da análise quantitativa, observou-se um aspecto positivo, pois atende a perspectiva de Lopes-Rossi (2002) que destaca a pertinência da abordagem dos gêneros textuais, pois proporcionará autonomia e domínio no funcionamento da língua em situações de comunicação dos alunos.

O primeiro capítulo do livro didático do $9^{\circ}$ ano aborda poemas como gênero central, e desenvolve atividades, reflexões e produção textual a partir do mesmo. Introduz abordando que no meio de comunicação houve transformações no jeito de empregar as linguagens, destacando que às mudanças na língua não só acontecem na publicidade, mídias, mas também em manifestações artísticas: música, teatro, pintura, literatura. Nota-se também na apresentação do 
gênero a presença de perguntas para conduzir o aluno a uma reflexão e também instigá-lo, " $\mathrm{E}$ como essas mudanças acontecem no poema, um gênero literário que sempre se caracterizou pela linguagem carregada de múltiplos significados, com a intenção de provocar o máximo de efeitos de sentido?" (p.20). Explana também uma alteração nas escolas de linguagem: "mais ousadas, reduzidas ou mais inusitada expressas nos poemas como forma de representar visões de mundo e sentimentos"(p.21). O capítulo apresenta poemas para comparações e para melhor compreensão do que fora mencionado. O manual didático aborda poema de Fernando Pessoa - "O amor, quando se revela" e o de José Paulo Paes - "Madrigal". Observemos a imagem abaixo para ilustrar o que fora mencionado:

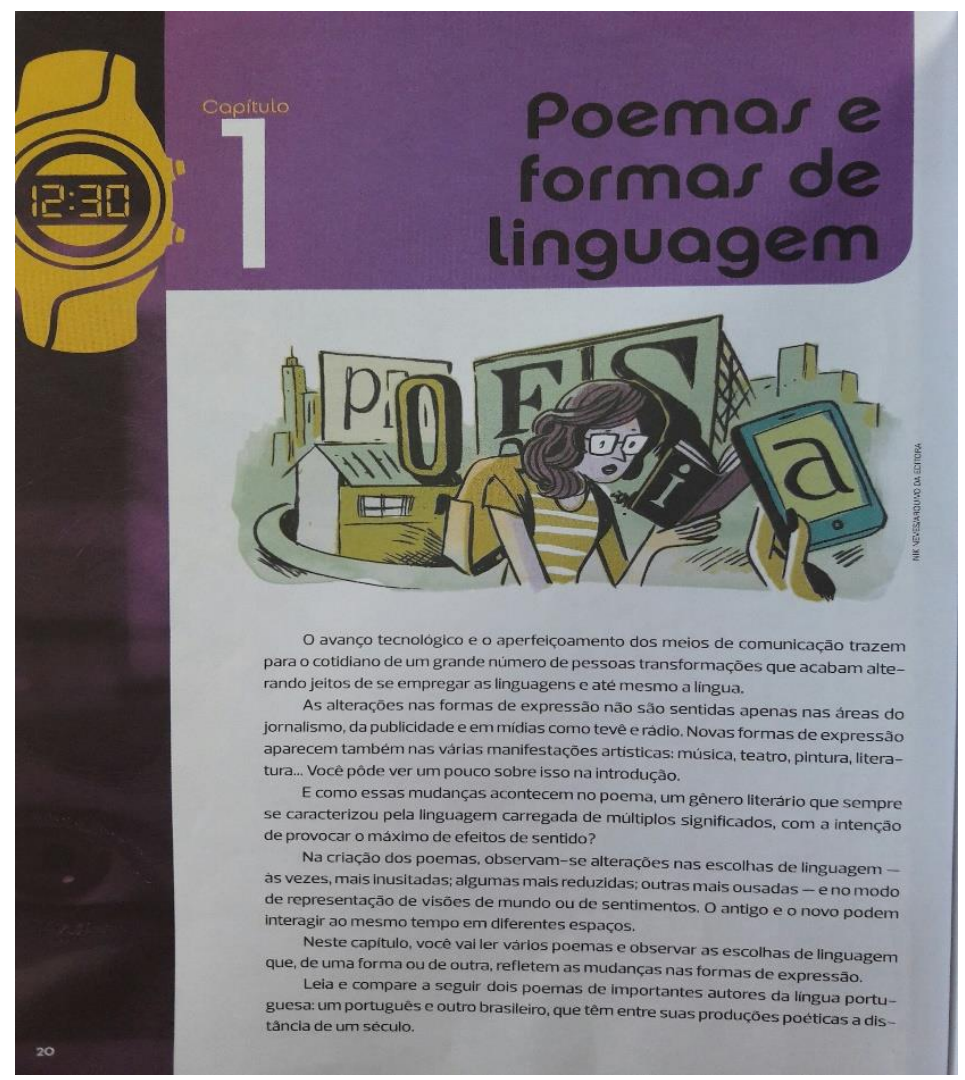

Figura 1 - Fonte: Coleção Teláris de Língua Portuguesa $-9^{\circ}$ ano

Dentro da perspectiva da abordagem sobre a oralidade, a proposta é que os alunos declamem os poemas lidos no início do capítulo; em grupo os alunos treinem a leitura expressiva do poema de Fernando Pessoa e de José Paulo Paes. O livro didático aborda a importância da leitura expressiva e significativa e da necessidade de treinar considerando a entonação. Posteriormente, em um momento previamente combinado pelo professor, cada grupo deverá apresentar. Também tem a opção da apresentação de uma leitura de forma uníssona ou uma leitura jogralizada. Por fim, a avaliação é para observar se os alunos conseguiram enriquecer os sentidos dos poemas por meio da entonação expressiva dos versos. 
Na seção "Língua: usos e reflexões" abordam os fenômenos gramaticais e neste capítulo estuda-se período composto, pontuação, expressividade e efeitos de sentido; recursos estilísticos: figuras de linguagem. As definições seguem da seguinte maneira: as explicações são contextualizadas a partir de poemas, partindo assim do texto para a explicação, posteriormente, a definição e reflexão das escolas da linguagem nos poemas, finalizando com atividades. Observemos a imagem a seguir.

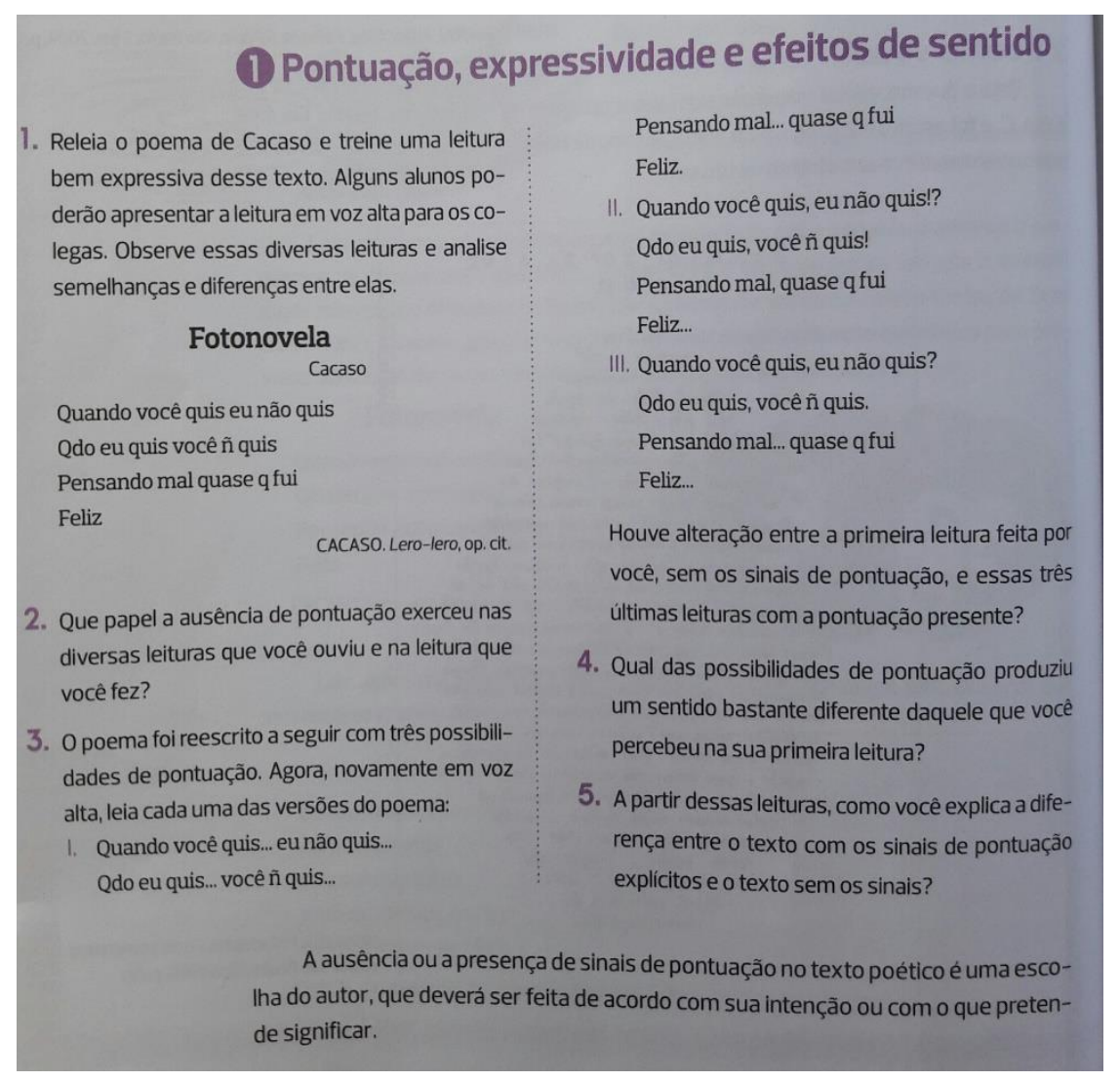

Figura 2 - Fonte: Coleção Teláris de Língua Portuguesa - $9^{\circ}$ ano

O objetivo da atividade é destacar que os sinais de pontuação no texto poético é uma escolha do autor, sendo que deve ser feita de acordo com a intenção ou com o que pretende significar, faz com que o aluno reflita essa perspectiva. Como pode ser observado na questão 2 “Que papel a ausência de pontuação exerceu nas diversas leituras que você ouviu e na leitura que fez do poema"(p.34). Tem-se também na primeira alternativa a leitura expressiva do poema, desenvolvendo assim uma atividade oral e articulada. Ainda analisando a atividade, na questão 3 solicita que o aluno faça a leitura do poema três vezes com as pontuações diferentes, após isso o LD solicita que o aluno faça uma reflexão "Houve alteração entre a primeira leitura, sem os sinais de pontuação e as três últimas leituras com a pontuação presente? (p.34), fazendo 
com que o aluno não oralize apenas a partir dos textos escritos, mas sim, leitura com expressividade, análise do que está lendo e reflexão do conteúdo gramatical.

Ante o exposto, nota-se que atende a uma das perspectivas do PCNs (1998) que salienta que não se deve tratar o ensino gramatical desarticulado das práticas de linguagem, destacando que não se deve trabalhar a gramática de forma descontextualizada, bem como uma prática pedagógica vai da metalinguagem para a língua por meio de exemplificação, e na atividade analisada parte da exemplificação que é o gênero poema bem como não aborda aspectos gramaticais desarticulado do texto. Outra atividade analisada sob a perspectiva do trabalho com a gramática é relacionada às orações compostas. Observe a imagem a seguir:

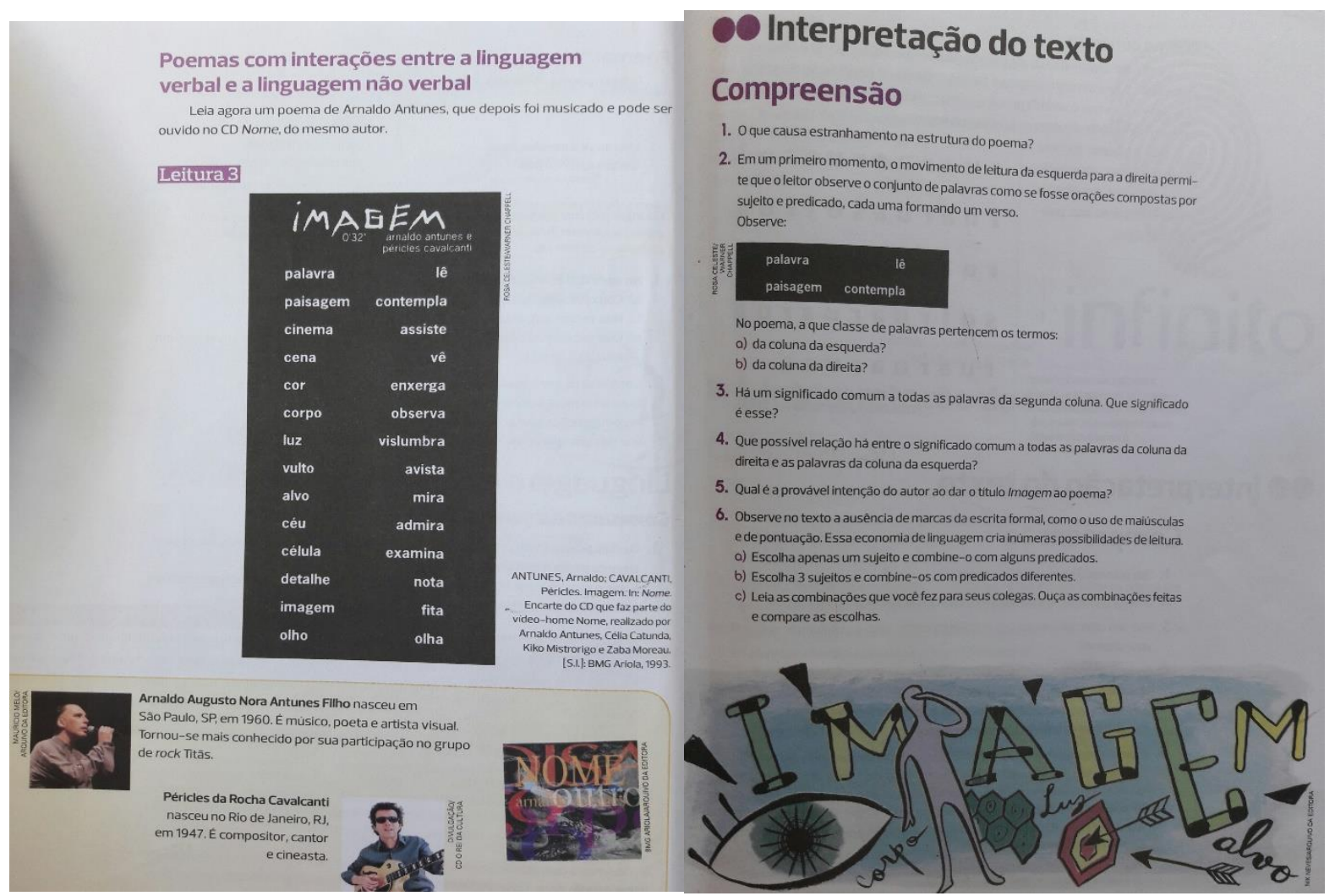

Figuras 3 e 4 - Fonte: Coleção Teláris de Língua Portuguesa $-9^{\circ}$ ano

Tem-se a perspectiva de abordar a interação entre a linguagem verbal e a linguagem não-verbal. A atividade parte do poema concreto de Arnaldo Antunes, que depois foi musicalizado no $C D$ Nome. A primeira questão desenvolve uma reflexão do aluno a partir da leitura, pois solicita que ele descreva o que sentir após a leitura; bem como em outra questão “qual é a provável intenção do autor ao dar o título Imagem ao poema?”(p.27), na questão 2, solicita apenas que o aluno defina qual classe pertence as palavras, um exercício apenas de 
definição. Na atividade tem a reflexão sobre a ausência da escrita formal no poema e que a partir disso criam-se inúmeras possibilidades de leitura, nessa questão faz com que o aluno faça combinações das orações, sujeito e predicado, a partir do texto para posteriormente discutir com o colega as combinações feitas para comparar.

Esta atividade não é um texto como pretexto e tem com o objetivo de copiar respostas prontas - embora em uma questão a solicite -, pois explora a reflexão dos alunos a partir do poema, a compreensão a partir do significado do título. Percebe-se que a atividade parte do gênero para a explicação, contextualizando o conteúdo e o conhecimento com os gêneros. Observa-se que explora a leitura, interpretação, escrita bem como a capacidade de reflexão na atividade, pois pergunta a opinião em quase todas as questões.

Outra atividade analisada sob a perspectiva do trabalho com a gramatica é o conteúdo de recurso estilístico: figuras de linguagem. Segue-se da seguinte maneira: leitura do trecho do gênero textual poema de Castro Alves - $\mathrm{O}$ gondoleiro do amor, definição do conceito e atividade. Analisemos a atividade a seguir para análise:

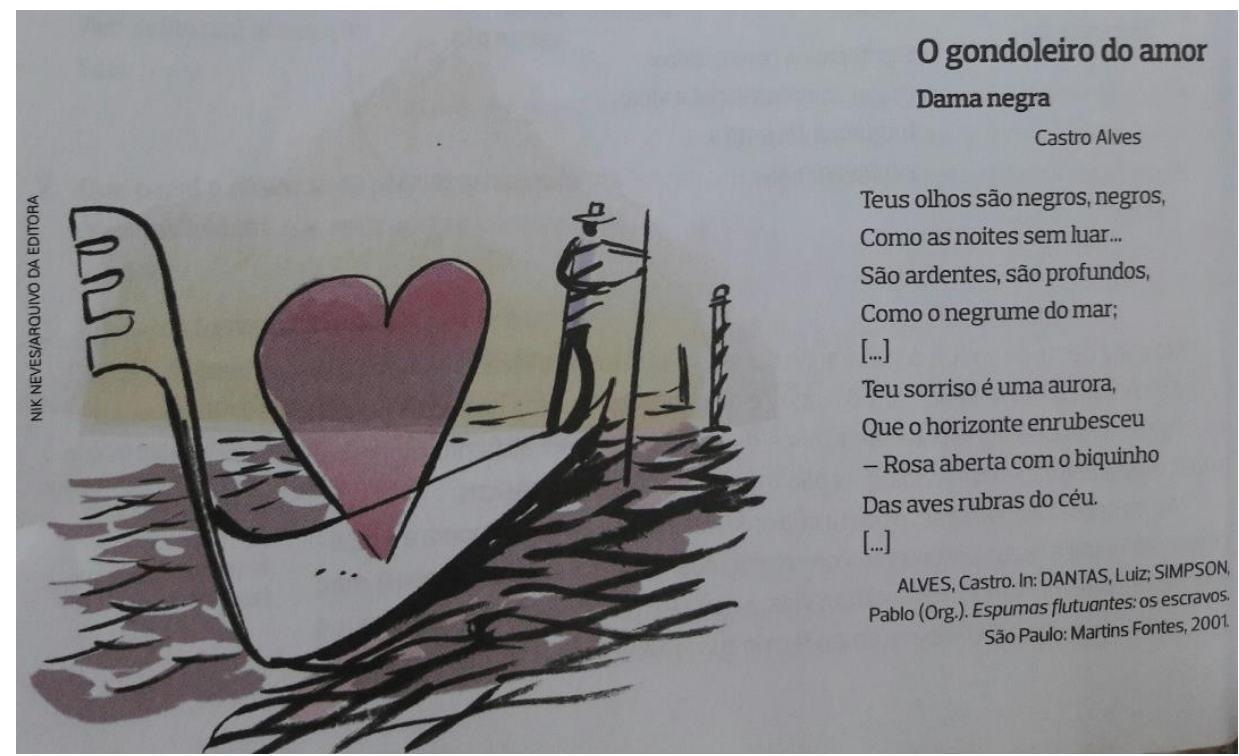

Figura 5- Fonte: Coleção Teláris de Língua Portuguesa - $9^{\circ}$ ano 


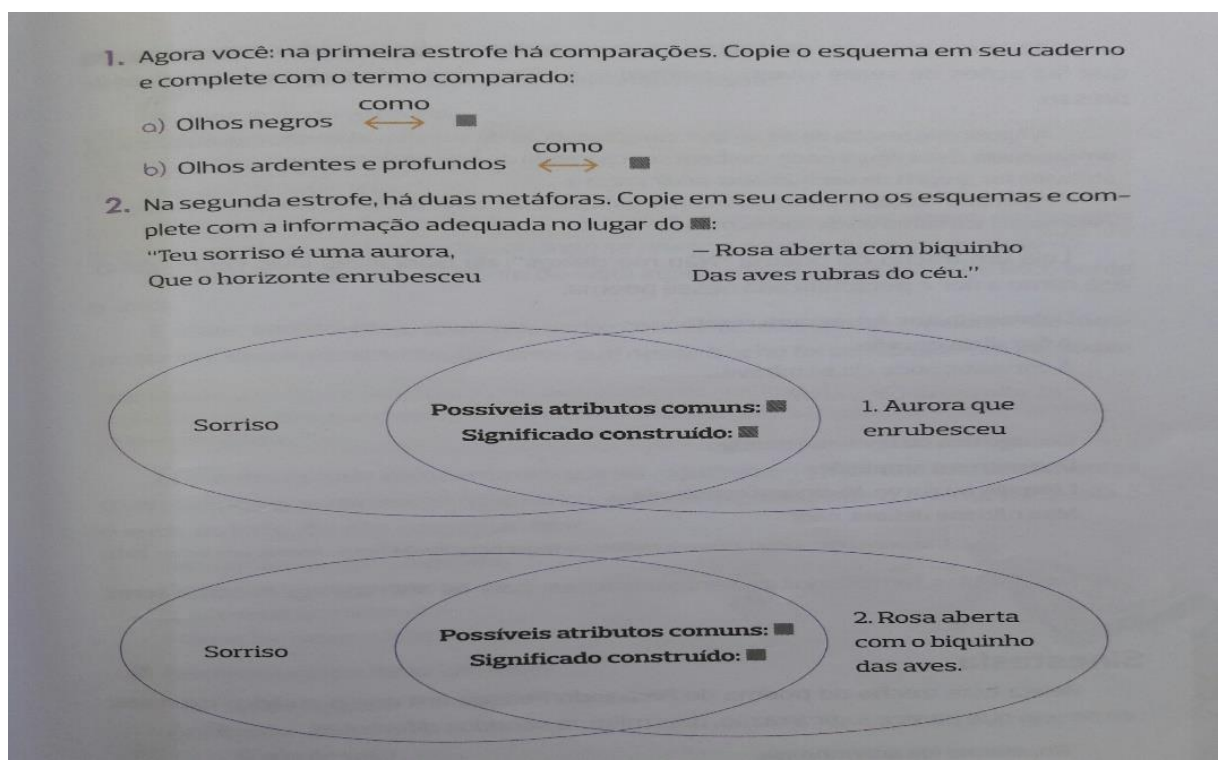

Figura 6 - Fonte: Coleção Teláris de Língua Portuguesa $-9^{\circ}$ ano

A partir da atividade notamos que na primeira questão não tem reflexão do aluno, sendo apenas para copiar do texto o trecho que consta a figura de linguagem; e na segunda questão também não tem a reflexão, análise do trecho, apenas retirar do texto os fragmentos que constam as figuras de linguagem e copiar. Nesta atividade, percebemos que parte de um gênero, não sendo descontextualizada, como pretexto, desenvolvendo um único objetivo que é analisar as classes gramaticais; não leva o aluno a refletir sobre, discutir sobre o texto antes de observar as classes gramaticais. Encontramos em algumas atividades essa intenção dos livros didáticos analisados, deixando de contextualizar e observar a função dos conteúdos gramaticais.

Portanto, nota-se que quando o livro didático estabelece uma prática constante de leitura de textos escritos, de produção de textos orais e escritos, contribui por meio de análise e reflexão sobre os múltiplos aspectos envolvidos, a expansão e a construção de instrumentos que progressivamente ampliam a competência discursiva do aluno. Dentro dessas afirmações Marcuschi (2007) reitera que é notória a importância de conter tais recursos nos livros didáticos.

\section{ANÁLISE DO LIVRO DIDÁTICO DO 9 ANO - I UNIDADE - CAPÍTULO V ENTREVISTA JORNALÍSTICA}

O primeiro capítulo do livro didático do $9^{\circ}$ ano aborda Entrevista Jornalística como gênero textual central. Introduz, de forma gradual, o que seria uma entrevista, a forma como obtemos informações e como conduzir uma entrevista, bem como a distinção da entrevista oral 
e escrita e seus objetivos e o veículo onde será divulgado; as características desse gênero, a área, e por fim, faz com que o aluno reflita sobre e dialogue sobre o assunto, pois é posto "Imagine uma entrevista com quem faz da arte de desenhar sua profissão. Que informações você desejaria obter dessa conversa? Ganhar a vida desenhando costuma ser prazeroso" (p.150). Nota-se, a partir da introdução do capítulo, que tem o diálogo com os alunos, fazendoos participar da introdução do gênero e com perguntas voltadas para o senso crítico, pois leva o aluno a argumentar sobre, não apenas explicações conceituais e desfocadas do cotidiano.

Sob o viés do trabalho com a gramática, observa-se na seção "Língua: usos e reflexões" na qual aborda os fenômenos gramaticais. Neste capítulo, estudam-se orações subordinadas adjetivas, pronome relativo, orações subordinativas adjetivas restritivas e explicativa. $\mathrm{Na}$ abordagem das definições, segue-se da seguinte maneira: são trechos/ fragmentos retirados dos textos lidos no decorrer do capítulo para explicar o conteúdo, partindo assim do texto para a explicação e posteriormente atividades. Observe a imagem a seguir.

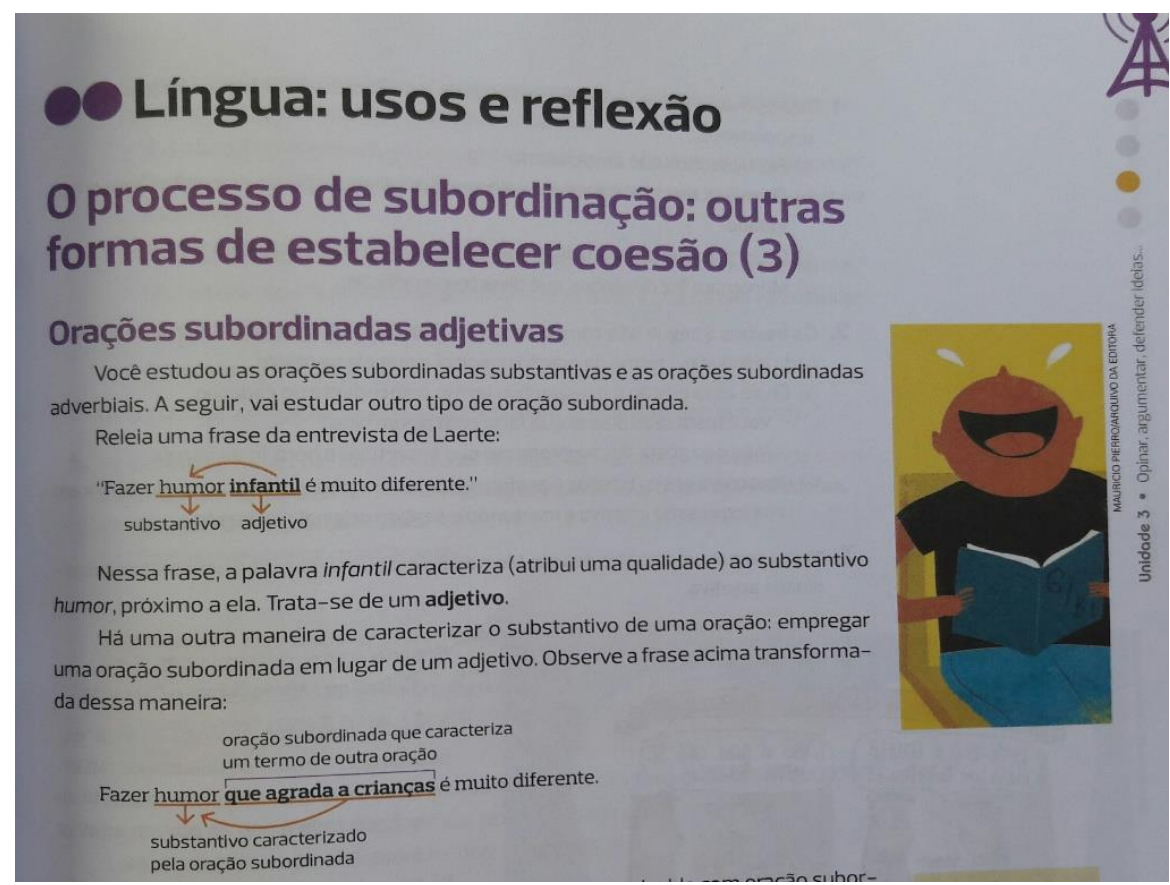

Figura 7 - Fonte: Coleção Teláris de Língua Portuguesa - $9^{\circ}$ ano

De acordo com o gênero textual tirinha, a primeira está relacionada ao que fora mencionado sobre de que forma são abordados os conceitos gramaticais e a segunda é uma atividade. $\mathrm{Na}$ atividade observa-se que são alternativas com frases e solicita que o aluno reescreva a frase substituindo por um adjetivo correspondente, observe a primeira questão. Dessa forma, constata-se uma atividade de mera repetição e substituição, não levando o aluno 
a refletir sobre as classes gramaticas, mas apenas copiar, nota-se isso, pois as assertivas são: "Reescreva as frases a seguir substituindo a oração destacada", "Copie do texto"; "Em seu caderno copie a oração subordinada adjetiva" ou "Identifique a oração subordinada adjetiva" (p.168).

Constata-se que nas assertivas analisadas, o texto é pretexto, pois são grifadas as palavras para análise e de forma mecânica o aluno deve apenas, rescrever, copiar, identificar, não consta uma alternativa que faz o aluno a refletir sobre a gramática normativa, fazendo com que a atividade não dê conta de desenvolver reflexão nos alunos. Identifica-se que essas atividades fomentam os alunos a terem dificuldades em escrever, pois, o ensino de gramática é fragmentado e separado da estrutura textual.

Outra atividade analisada sob a perspectiva da abordagem do ensino de gramática, é o conteúdo orações subordinadas adjetivas restritivas. A explicação segue-se com leitura de fragmento do texto, sublinhando na oração a classe gramatical e posteriormente de forma descritiva expondo os conceitos, os significados dentro da oração. Observe a imagem a seguir.

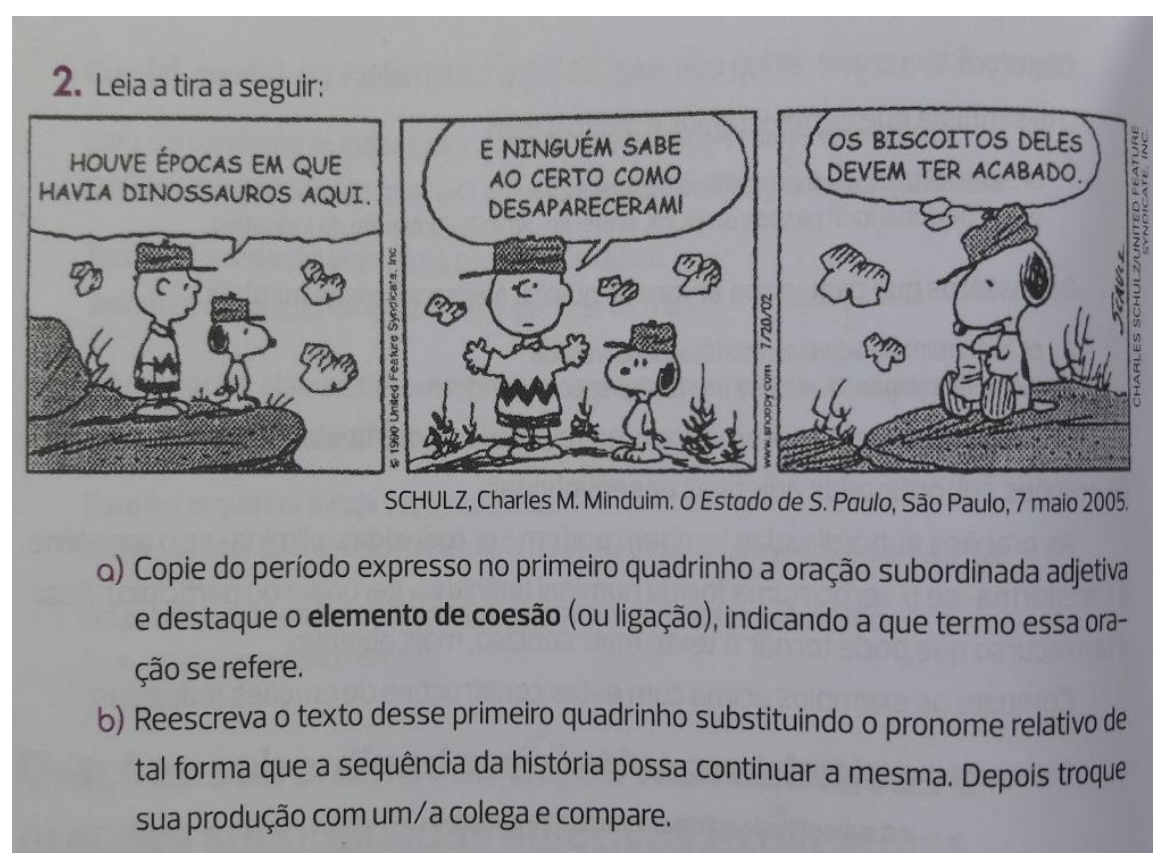

Figura 8 - Fonte: Coleção Teláris de Língua Portuguesa - $9^{\circ}$ ano

As perguntas partem do gênero para a explicação, faz com que o aluno conheça, desenvolva a leitura, porém as assertivas exploram pouco a reflexão do aluno, sendo apenas perguntas como: "Copie do período expresso no primeiro quadrinho"; ou "Reescreva o texto desse primeiro quadrinho" (p.172), sendo apenas um exercício de reescrita e definição das 
classes gramaticais e busca no texto o que é solicitado, ou fragmentos do texto sublinhado para definir o período.

Nota-se, portanto, uma atividade que ensina por meio de frases e palavras soltas, desvinculadas de um contexto, considerando que as palavras soltas apresentam um sentido diferente daquelas que estão dentro de um contexto, pois, o que determina o sentido exato do léxico é o contexto em que ela estiver inserida.

Assim, volta-se para um ensino de atividades de gramática compostas por palavras retiradas do texto sem função, que servem apenas como lição, sendo um ensino pautado na nomenclatura gramatical.

Desse modo, o discente só será capaz de nomear e classificar as unidades linguísticas, sem o conhecimento dos efeitos que elas provocam nos textos em que são inseridas, também nota-se que solicita apenas grifar, circular ou identificar as unidades linguísticas, sem levar em consideração o funcionamento e a aplicabilidade da gramática nos textos escritos ou no fragmento das frases, sendo uma prática pedagógica baseada na nomenclatura.

Dessa forma, a partir da análise notou-se que o livro didático atende as sugestões dos PCNs (1998) que afirmam sobre a necessidade e importância de contemplar na escola e nos livros didáticos uma diversidade de gêneros para que o sujeito desenvolva habilidades de oralidade, leitura e escrita nos alunos.

\section{CONSIDERAÇÕES FINAIS}

Os resultados alcançados na pesquisa foram através de leitura do referencial teórico e análise quantitativa e qualitativa do livro didático do ensino fundamental II, do $9^{\circ}$ ano. Em relação à análise, primeiramente realizamos a contagem dos gêneros textuais e, posteriormente, de forma descritiva, analisamos a qualidade das atividades no livro para verificar se contempla de forma integrada o ensino de língua portuguesa.

No trabalho com a gramática, as explicações partem do gênero textual, o livro didático contextualiza as atividades, partindo da leitura e escrita, sendo que aborda, em alguns momentos, a função social, não sendo desarticulado das práticas de linguagem, pois, os exemplos postos são de linguagem formal e informal e de características coloquiais.

Porém, em alguns capítulos, observam-se frases retiradas do texto com a finalidade de analisar apenas a frase fora do contexto. Nota-se, portanto, uma forma linear de ensinar a gramática normativa, pois tem-se a definição, classificação e exercitação, abordando perguntas, comparações, situações, contribuindo,assim, para a reflexão do aluno. 
Quanto à diversidade de gêneros textuais presentes nos livros didáticos do $9^{\circ}$ ano, são apresentados 29 no total, são: música; quadro; fotografia; poema; mapa tabela; glossário; romance; pintura; tira; esquema; conto; crônica; resumo; noticia; debate; capa de livro; quadrinho; revista; gráfico; roteiro; charge; reportagem; artigo de opinião; logotipo; anuncio; haicai; texto científico; biografia. Nota-se que algumas atividades apresentam um conjunto de texto e indica o gênero e outras atividades não desenvolvem projetos de forma sistemática e deixa de mencionar os gêneros textuais.

Quanto à diversidade de gêneros orais presentes no livro didático do $9^{\circ}$ ano, são apresentados no total: peça teatral; dramatização; letra de música; filme; notícia; debate, seminário, propaganda, piada, anedota, desafio, fábula.

Diante do exposto, vale ressaltar que há mais gêneros escritos do que orais ${ }^{2}$; os capítulos apresentam um trabalho integrado com a leitura, escrita, intepretação e com a definição do gênero, pois desde o início é centrado no gênero poema (mesmo que aborde outros gêneros textuais) e explica sob várias perspectivas, isso faz com que o aluno compreenda sua forma e função com mais clarividência, tem-se portanto, reflexões do uso da língua não apenas conceitos e aplicabilidade.

Observa-se que o livro didático contempla uma diversidade de gêneros textuais e a cada capítulo o livro seleciona um em específico para o desenvolvimento do trabalho. O livro didático desenvolve de forma sequencial, integrada o trabalho da leitura, interpretação, produção de texto e análise linguística, contribuindo assim para a competência discursiva dos alunos, visto que é um dos objetivos propostos pelos PCNs (1998). Devemos salientar que, conforme análise apresentada, nem todos os capítulos abordam a sequência de forma integrada, mas observa-se que a maior parte encontra-se.

Os capítulos analisados abordam, em algumas atividades, as situações formais e informais da língua, evidenciando as variações linguísticas, e a cada capítulo o livro seleciona um gênero em específico para desenvolver habilidades na leitura, interpretação, produção de texto e análise linguística dos alunos.

Constata-se também a importância de analisar o livro didático, considerando que ele é uma ferramenta muito utilizada em sala de aula, dessa forma, seu processo de análise e escolha pelas unidades escolares deve ser pautado em uma análise crítica. Ainda nota-se que o material didático é considerado significativo para a formação de alunos de ensino básico, ressaltando sua importância como suporte metodológico para professores e ainda, em muitos contextos

\footnotetext{
${ }^{2}$ Constatou-se a afirmação a partir da análise da presença dos gêneros escritos e orais no livro didático do $6^{\circ}$ ao $9^{\circ}$ ano, mas o objetivo da pesquisa era mencionar apenas a quantidade dos gêneros orais.
} 
educacionais, como a única fonte de informação, de leitura e de base histórica.

\section{REFERÊNCIAS}

ANTUNES, I. Aula de português: encontro e interação. São Paulo: Parábola Editorial, 2003. BAZERMAN, C.; DIONÍSIO, A.P.; HOFFNAGEL, J.C. Gêneros textuais, tipificação e interação. 2.ed. São Paulo:Cortez, 2005.

BEZERRA, M. A. Ensino de língua portuguesa e contextos teóricos metodológicos. In: Gêneros textuais e ensino. 3. ed. Rio de Janeiro Lucerna, 2005.

BORGATTO, A.T., BERTIN, T., MARCHEZI, V. Coleção Teláris de Língua Portugesa $-9^{o}$ ano. São Paulo: Ática, 2012.

BRASIL. Secretaria de Educação Fundamental. Parâmetros curriculares nacionais: terceiro e quartos ciclos do ensino fundamental: língua portuguesa. Brasília: MEC/SEF, 1998.

COSTA VAL, M.G., MARCUSCHI, B. Livros didáticos de língua portuguesa: letramento e cidadania. Belo Horizonte: CEALE/Autêntica, 2005.

DIONÍSIO, A.P. MACHADO, A.R.; BEZERRA, M.A. Gêneros textuais e ensino. 3. ed. Rio de Janeiro Lucerna, 2005.

GERALDI, J.W. O texto na sala de aula. 3. ed.São Paulo: Ática, 1999.

LOPES-ROSSI, M.A.G. Gêneros Discursivos no Ensino de Leitura e Produção de Textos. Taubaté-SP: Cabral Editora e Livraria Universitária, 2002.

MARCUSCHI, B. , CAVALCANTE, M. Atividades de escrita em livros didáticos de Língua Portuguesa: Perspectivas convergentes e divergentes. In:MARCUSCHI, B., COSTA

VAL,M.G. (Orgs.)Livros didáticos de língua portuguesa: letramento e cidadania. Belo Horizonte :CEALE/Autêntica, 2005. p. 237-245.

MARCUSCHI, L. Gêneros textuais: definição e funcionalidade. In. DIONÍSIO, A.P. MACHADO, A.R. BEZERRA, M.A. (Orgs)- Gêneros Textuais e ensino. São Paulo: Parábola Editorial, 2010.

MEURER, J,L.; MOTTA-ROTH, D. (Orgs.) Gêneros textuais e práticas discursivas: subsídios para o ensino da linguagem. Bauru: Edusc, 2002.

POSSENTI, S. Por que (não) ensinar gramática na escola. Campinas: Mercado de Letras : ALB, 1998.

SOARES, M. Letramento: um tema em três gêneros. Belo Horizonte, Autêntica. 2003.

TRAVAGLIA, L.C. Gramática e interação: uma proposta para o ensino de gramática no $1^{\circ} \mathrm{e}$ $2^{\circ}$ graus. São Paulo: Cortez, 2001. 